\title{
Bilateral Nonsyndromic Cystic Lesions Involving Impacted Teeth: Nomenclature and Diagnostic Protocol
}

\author{
Aashka Sethi ${ }^{1}$, Devi C Shetty ${ }^{2}$, Ankita Tandon ${ }^{3}$, Nida Afroz ${ }^{4}$
}

\begin{abstract}
Aim: To present a brief overview of etiopathogenesis, nomenclature, and treatment modality for a case of nonsyndromic bilateral cysts in the mandible.

Background: Odontogenic cysts, though comprise a distinct group of lesions have on and off posed challenges in etiopathogenesis and nomenclature. The prima facia role of development/inflammation in the buildup of fluid between the reduced enamel epithelium attached at the cementoenamel junction and the enamel in the pathogenesis of dentigerous cysts has long been discussed. Along with this, the spread of inflammatory exudate from an overlying primary tooth could also be the source of an inflammatory dentigerous cyst.

Case description: Bilateral swellings in a 12-year-old patient presented with a chief complaint of pain in the lower jaw for 4 months. The radiographic picture exhibited unilocular, well-circumscribed radiolucent areas extending from 34 to 37 on the left side and from 44 to 47 on the right side of the mandible and involving retained mandibular second premolars on both sides.

Conclusion: Mere expansion of a follicle due to inflammation from an overlying infected/necrosed/treated primary tooth in which the reduced enamel epithelium does not appear to be attached at the cementoenamel junction should be aptly referred to as an "inflammatory follicular cyst". Clinical significance: The present article attempts to illuminate the notable differences between dentigerous cysts and inflammatory follicular cysts of jaws which requires an adequate distinction in pediatric cases for diagnostic and management considerations.

Keywords: Cyst, Dentigerous, Follicular, Unilocular.

International Journal of Clinical Pediatric Dentistry (2020): 10.5005/jp-journals-10005-1795
\end{abstract}

\section{BACKGROUND}

Odontogenic and nonodontogenic cysts of the oral and maxillofacial tissues are primarily ellipsoid, radiolucent, and demarcated. They develop during the process of odontogenesis or after, and are derived from odontogenic epithelium of stomodeal origin. ${ }^{1}$ A dentigerous cyst is an epithelial-lined cavity that encompasses the crown of an impacted tooth and forms an attachment at the cementoenamel junction. They account for approximately $24 \%$ of all true cysts in the jaws. ${ }^{2}$ Diverse theories have been put forth to explain the cause of the expansion of the follicle of an impacted tooth in the pathogenesis of the cyst. While some authors suggest developmental melee during the early stages of odontogenesis as the source, ${ }^{3}$ others consider an inflammatory stimulus from a deciduous predecessor to be the initiator of the cyst in the permanent successor. ${ }^{4,5}$ However, it must be emphasized that cystic lesions that arise via the latter pathogenetic concept are clinically and histopathologically disparate from developmental dentigerous cysts and should be referred to as inflammatory follicular cysts. ${ }^{6}$ It should be noted that most dentigerous cysts are solitary lesions. On the contrary, bilateral and multiple cysts are a feature of syndromes, such as cleidocranial dysplasia, Maroteaux-Lamy syndrome, and mucopolysaccharidosis. ${ }^{7}$ Therefore, in the absence of syndromic characteristics, the clinical and histopathological traits of cases reported as bilateral "dentigerous" cysts associated with permanent teeth under a necrotic primary tooth should be perused to rightly denominate them as inflammatory follicular cysts; that clarifies the origin of these cysts and to some extent modifies their treatment strategy.

\section{Case Description}

A 12-year-old boy presented with a chief complaint of pain and swelling in the lower jaw on the right side. He reported a gradual
${ }^{1-4}$ Department of Oral and Maxillofacial Pathology and Oral Microbiology, ITS Centre for Dental Studies and Research, Ghaziabad, Uttar Pradesh, India

Corresponding Author: Aashka Sethi, Department of Oral and Maxillofacial Pathology and Oral Microbiology, ITS Centre for Dental Studies and Research, Ghaziabad, Uttar Pradesh, India, Phone: +91 8171828656, e-mail: sethiaashka90@gmail.com

How to cite this article: Sethi A, Shetty DC, Tandon A, et al. Bilateral Nonsyndromic Cystic Lesions Involving Impacted Teeth: Nomenclature and Diagnostic Protocol. Int J Clin Pediatr Dent 2020;13(4):429-432.

Source of support: Nil

Conflict of interest: None

increase in the size of the swelling which had persisted for 4 months. On examination, a diffuse swelling was noted extending anteroposteriorly from 34 to 36 tooth region on the left side and 44 to 46 region on the right side and superoinferiorly from the gingival margin to the lower border of the mandible (Fig. 1). The swellings measured approximately $2 \times 3 \mathrm{~cm}$ in size and were of the same color as the surrounding mucosa. On palpation, both swellings were soft in consistency, with smooth margins and were nontender. Panoramic radiographs showed unilocular, wellcircumscribed radiolucent areas extending from 34 to 37 on the left side and 44 to 47 on the right side of the mandible and involving retained mandibular second premolars on both sides (Fig. 2). Cone-beam computed tomography (CBCT) was used to obtain a three-dimensional image, enabling the exact location and extent of the lesions. Cone-beam computed tomography examination of the left mandibular region showed well-defined, well-corticated 
expansile osteolytic radiolucency measuring approximately $36.1 \times 23.6 \times 16.0 \mathrm{~mm}$ in its greatest anteroposterior, superoinferior, and transverse dimensions (Fig. 3A). The radiolucency on the

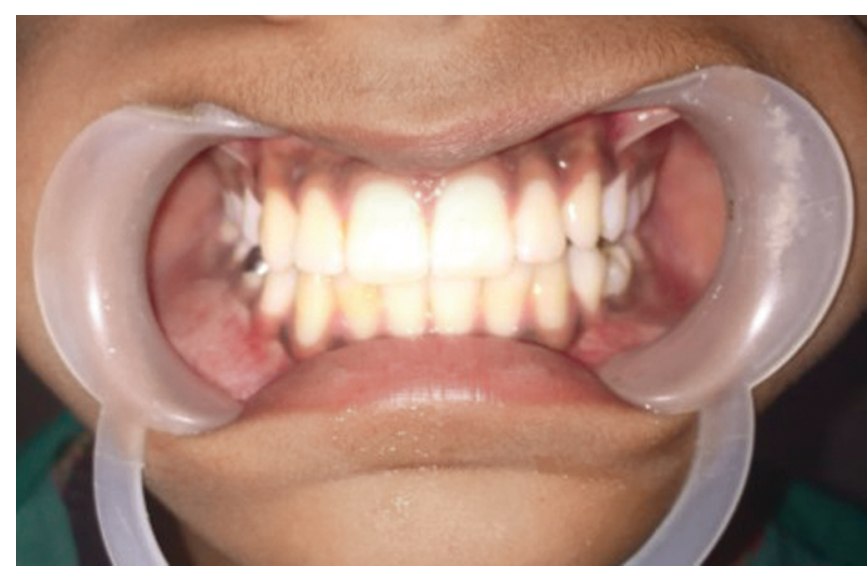

Fig. 1: Intraoral swellings seen in the left and right lower back tooth region

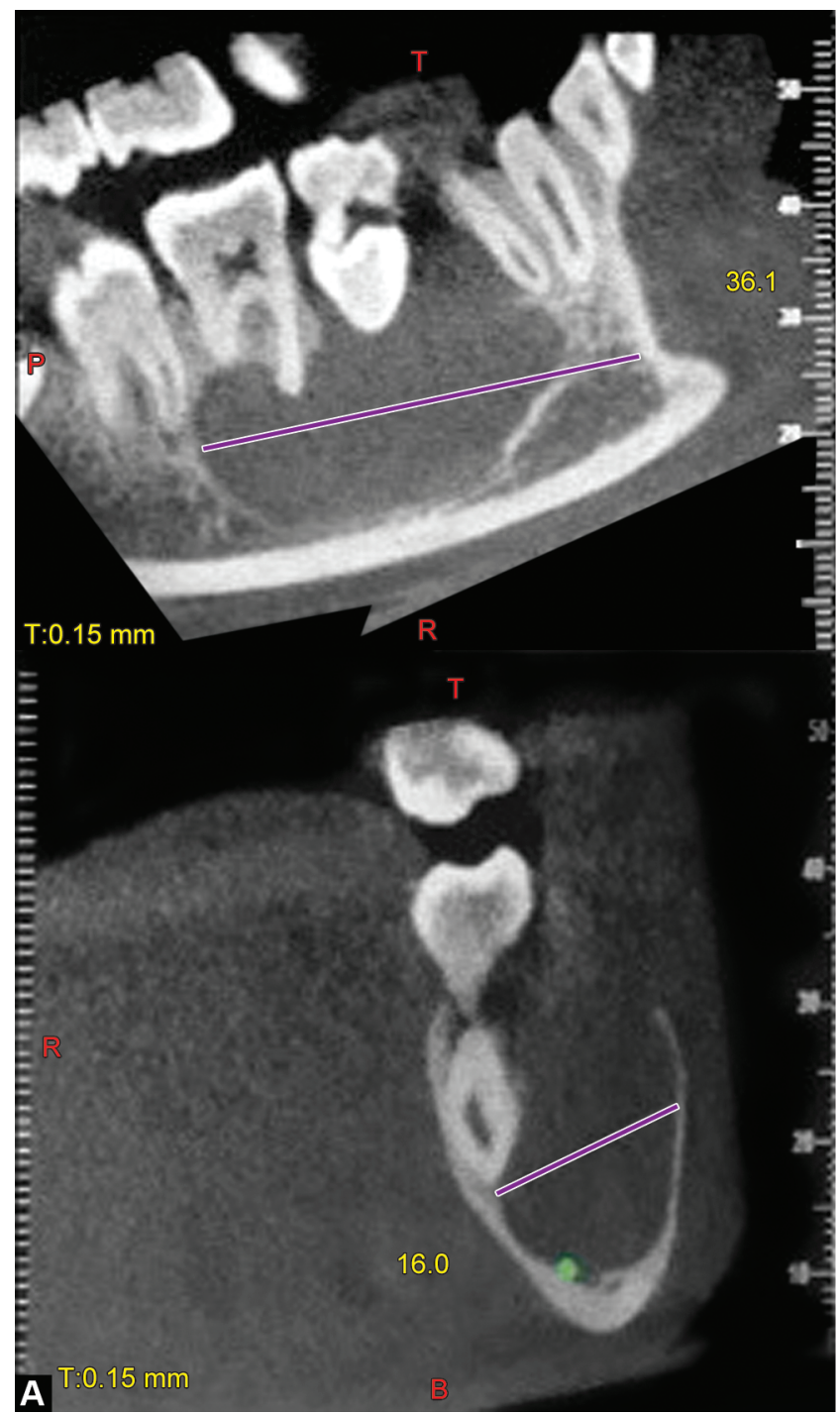

right side was approximately $38.0 \times 28.7 \times 19.4 \mathrm{~mm}$ encroaching the inferior border of the mandible (Fig. 3B). Furthermore, the systemic evaluation of the patient for syndromic features, such as malocclusion, condylar defects, gingival hyperplasia, and maxillary micrognathia, was confirmed negative. Hence, based

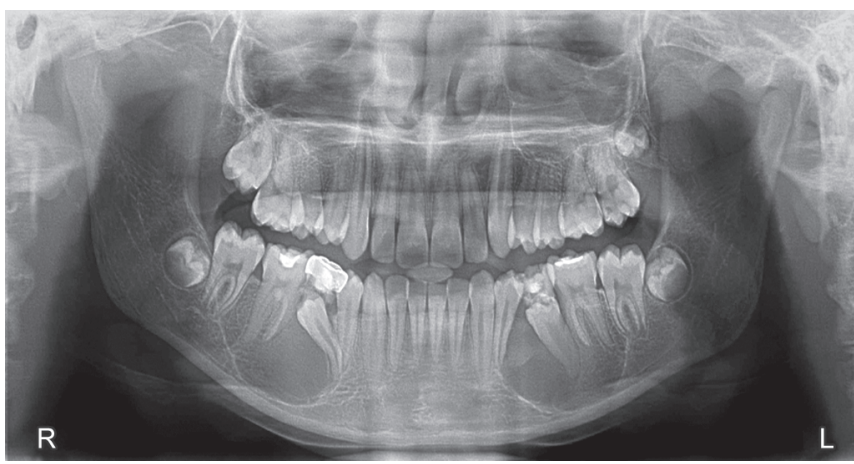

Fig. 2: Panoramic radiograph shows bilateral well-defined radiolucencies associated with 35 and 45 and extending from 34 to 37 and 44 to 47 , respectively

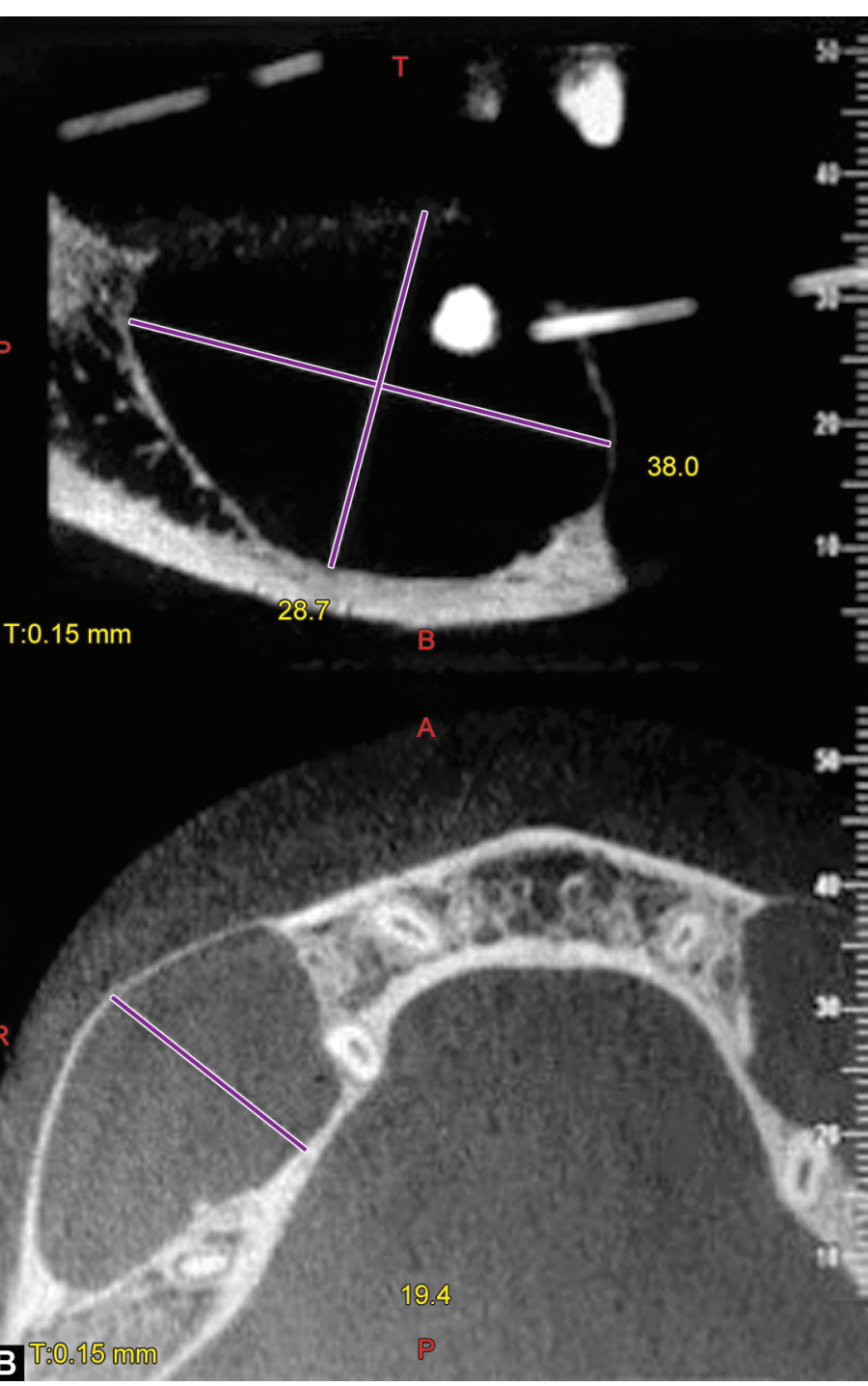

Figs $3 \mathrm{~A}$ and B: Cone-beam computed tomography showing the anteroposterior, superoinferior, and transverse extensions of the lesion in the left mandibular region. (A) Left side; (B) Right side 


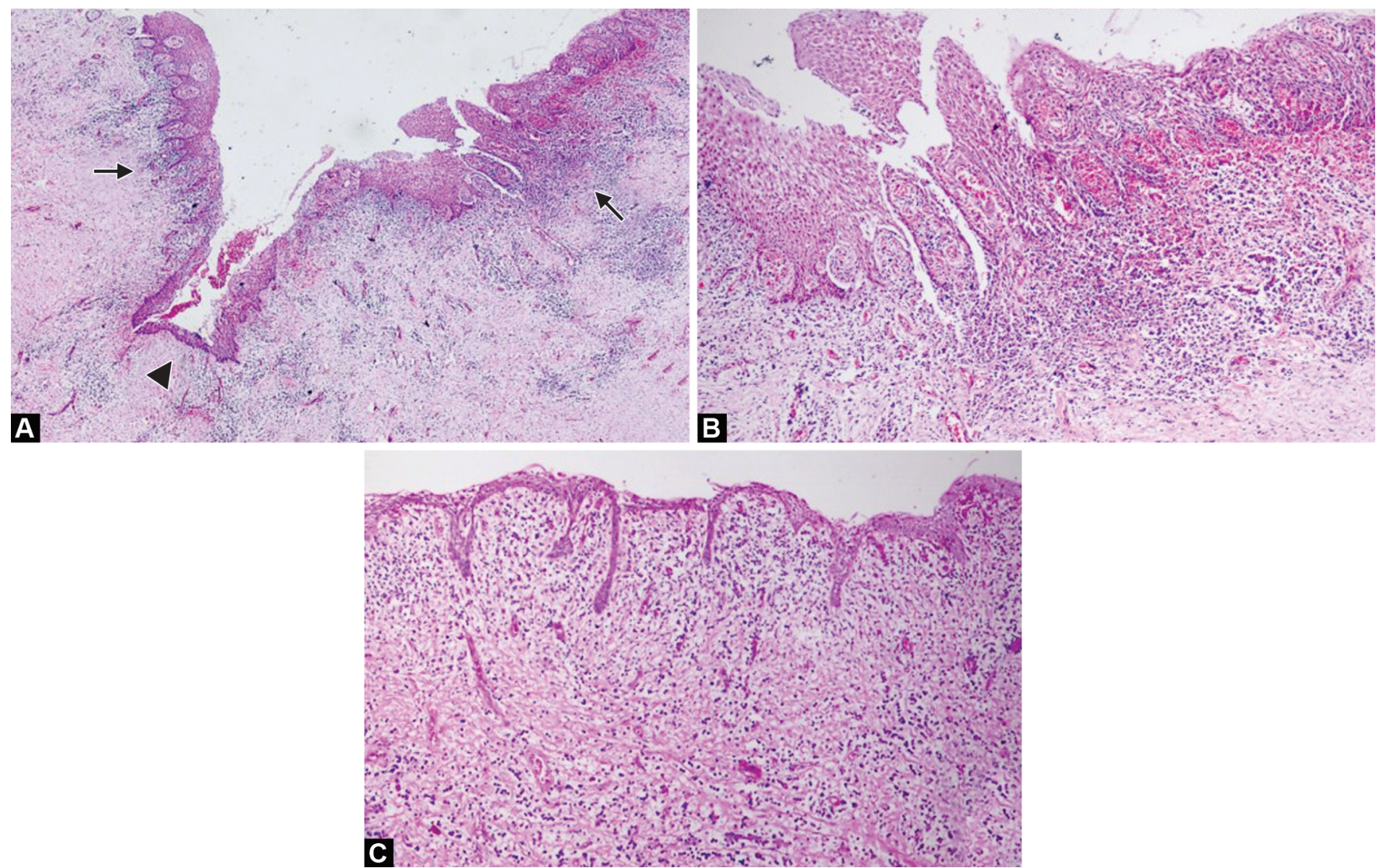

Figs 4A to C: (A) Left side: Cystic epithelium with nonkeratinized stratified squamous epithelium (arrowhead, H\&E stain, 4X); (B) Left side: Arcading pattern overlying areas of dense inflammation (H\&E stain, 10X); (C) Right side: Hyperplastic stratified squamous epithelium overlying chronic inflammation (H\&E stain, 10X)

on the clinical and radiographic findings, a provisional diagnosis of a nonsyndromic benign odontogenic cyst was established for both lesions. The biopsy specimen consisted of four soft tissue bits with the largest one measuring approximately $2.5 \times 2 \times 1 \mathrm{~cm}$ and smallest measuring $0.5 \times 0.5 \times 0.4 \mathrm{~cm}$ in size, brown in color, and soft in consistency. Histopathological examination of the cystic lesion on the left side revealed a 4 to 5 cell layered nonkeratinized epithelium overlying an inflamed connective tissue capsule (Fig. 4A arrowhead). A proliferative hyperplastic epithelium in an arcading pattern was noted in many areas under the influence of an intense juxtaepithelial inflammatory infiltrate (Fig. 4A arrows and Fig. 4B). The lesion on the right side demonstrated a thin nonkeratinized stratified squamous epithelium with many hyperplastic areas and a connective tissue with chronic inflammatory cell infiltrate (Fig. 4C). The findings were suggestive of inflammatory follicular cyst on either side.

\section{Discussion}

The WHO classification of odontogenic and maxillofacial bone tumors categorizes odontogenic and nonodontogenic cysts based on their origin; into inflammatory and developmental cysts. ${ }^{8}$ Dentigerous cysts are the most common developmental odontogenic cysts and may be either extrafollicular or intrafollicular in origin. The former consists of degeneration of the stellate reticulum during odontogenesis and is associated with enamel hypoplasia. The latter may develop through the pressure exerted by an erupting tooth on an impacted follicle which leads to the obstruction of venous outflow, resulting in transudation of serum across the capillary wall and its accumulation either between the reduced enamel epithelium and the enamel or within the enamel organ itself. ${ }^{3}$ Another theory of origin that has been proposed is that periapical infection from an over-retained deciduous tooth may produce cystic manifestations in the follicle of an impacted successor permanent tooth. ${ }^{5}$ However, it should be noted that cysts that develop under the influence of deciduous periapical pathology arise from the antigenic stimulus and do not hold the developmental traits of dentigerous cysts. Such cysts should be regarded as "inflammatory follicular cysts". The present case is an example in which both the mandibular premolars (35 and 45) were associated with over-retained pulpotomized deciduous teeth (75 and 85).

Of all the odontogenic cysts, the incidence of dentigerous cysts is second only to radicular cysts. However, the concurrence of multiple dentigerous cysts in a nonsyndromic patient is an exceptional phenomenon. Nonetheless, a significant number of case reports suggest the prevalence of nonsyndromic bilateral/ multiple dentigerous cysts in both maxillary and mandibular arches. ${ }^{9-11}$ The lack of syndromic traits, however, is not unpredicted in these cases as they occur around an infectious focus about a deciduous or permanent tooth. Hence, some, if not all such cases are de facto inflammatory follicular cysts and do not represent nonsyndromic dentigerous cysts. Table 1 highlights the traits that distinguish dentigerous cysts from inflammatory follicular cysts and holds significance in the present context. 
Table 1: Differences between developmental dentigerous cyst and inflammatory follicular cyst

\begin{tabular}{|c|c|c|}
\hline Features & Dentigerous cyst & $\begin{array}{l}\text { Inflammatory } \\
\text { follicular cyst }\end{array}$ \\
\hline Etiopathogenesis & Developmental lesion & Inflammatory lesion \\
\hline Age & 2nd and 3rd decade & 1st or 2nd decade \\
\hline $\begin{array}{l}\text { Most commonly } \\
\text { associated tooth }\end{array}$ & Mandibular third molars & $\begin{array}{l}\text { Permanent } \\
\text { successors of primary } \\
\text { necrotic teeth }\end{array}$ \\
\hline $\begin{array}{l}\text { Number of cystic } \\
\text { lesions }\end{array}$ & Mostly solitary & May be multiple \\
\hline Symptoms & Asymptomatic & Symptomatic \\
\hline Histopathology & $\begin{array}{l}\text { Thin epithelium } \\
\text { of } 2-4 \text { layers of } \\
\text { undifferentiated } \\
\text { cells derived from } \\
\text { the reduced enamel } \\
\text { epithelium. The fibrous } \\
\text { cyst wall is relatively } \\
\text { uninflamed }\end{array}$ & $\begin{array}{l}\text { Nonkeratinized, } \\
\text { stratified, squamous } \\
\text { epithelium of varying } \\
\text { thickness with focal } \\
\text { areas of arcading and } \\
\text { inflamed connective } \\
\text { tissue }\end{array}$ \\
\hline
\end{tabular}

Inflammatory follicular cysts arising from necrotic primary teeth are primarily observed in the first two decades during the mixed dentition period. The age of occurrence could be another reason why these cysts are confounded with dentigerous cysts. Diagnostic radiographs that show follicular cysts under primary teeth can also be misinterpreted as an "incidental" finding of bilateral dentigerous cysts of the circumferential type in which the crown and a significant portion of the root appears to lie within the cyst.

The distinctive microscopic picture in the present case serves to support the argument. The cystic lining was composed of arcades of proliferating epithelium atop areas of dense inflammation in the connective tissue. On the one hand, areas devoid of an exuberant inflammatory infiltrate were noted to have a quiescent epithelial lining. Dentigerous cysts, on the other hand, enclose a thin epithelium of undifferentiated cells derived from the reduced enamel epithelium and a relatively uninflamed connective tissue capsule. The localized proliferation of the epithelial lining in inflamed dentigerous cysts and the ensuing proliferation of the basal cells into the fibrous connective tissue must be assessed and differentiated from inflammatory follicular cysts.

A recent report states that pulpectomy of deciduous teeth with zinc oxide eugenol or a formocresol pulpotomized primary tooth may give rise to odontogenic cysts in the jaws. ${ }^{12}$ In such cases, it is unclear if the cyst arises from the antigenic stimulus within the pulp or the obturating material. Nevertheless, it would seem prudent to distinguish inflammatory follicular cysts from dentigerous cysts to effectuate proper treatment modalities. The treatment plan for dentigerous cysts depends on the position, angulation, root maturity of the cyst-related teeth, and the potential for eruption of the impacted tooth. Extraction of the affected primary tooth followed by marsupialization is deemed to be the best way to conserve the permanent tooth in inflammatory follicular cysts. ${ }^{13}$ In the present case, the deciduous teeth were extracted followed by orthodontic traction of both the mandibular second premolars.

\section{ConCLUSION}

Bilateral odontogenic cysts associated with mandibular second premolars are a rare entity. A case of multiple dentigerous cysts should prompt a thorough clinical and radiographic examination to identify possible syndromic correlation. It should be recalled that bilateral inflammatory follicular cysts associated with impacted teeth may mimic developmental dentigerous cysts. Therefore, essential features such as attachment of the cyst lining to the cervical margin of the tooth and the microscopic presence of reduced enamel epithelium lining the wall of the cyst should be identified before a diagnosis of dentigerous cyst is made. The present case report also emphasizes the importance of regular follow-up of infected/pulpectomized deciduous teeth.

\section{Clinical Significance}

The article presents the clinical and histopathological features of bilateral mandibular inflammatory follicular cysts and gives an insight into the pathogenesis of the same. Given the radiographic resemblance of this pathology with dentigerous cysts, we have attempted to illuminate the notable differences between the two lesions. The article also strives to underscore the importance of appropriate nomenclature in pediatric oral pathology, which may be valuable to the pedodontist for treatment planning in everyday practice.

\section{References}

1. Goaz PW, White SC. Oral radiology: principles and interpretation. 3rd ed., St Louis, Mo: Mosby-Year Book; 1994. pp. 398-676.

2. Daley TD, Wysocki GP, Pringle GA. Relative incidence of odontogenic tumors and oral and jaw cysts in a Canadian population. Oral Surg Oral Med Oral Pathol 1994;77(3):276-280. DOI: 10.1016/00304220(94)90299-2.

3. Al-Talabani NG, Smith CJ. Experimental dentigerous cysts and enamel hypoplasia: Their possible significance in explaining the pathogenesis of human dentigerous cysts. J Oral Pathol 1980;9(2): 82-91. DOI: 10.1111/j.1600-0714.1980.tb01390.x.

4. Shibata Y, Asaumi J, Yanagi Y, et al. Radiographic examination of dentigerous cysts in the transitional dentition. Dentomaxillofac Radiol 2004;33(1):17-20. DOI: 10.1259/dmfr/24148363.

5. Benn A, Altini M. Dentigerous cysts of inflammatory origin. A clinicopathologic study. Oral Surg Oral Med Oral Pathol Oral Radiol Endod 1996;81(2):203-209. DOI: 10.1016/s1079-2104(96)80416-1.

6. Marques NP, Marques NCT, Sakai VT, et al. Inflammatory follicular cysts associated to necrotic primary teeth. Eur Arch Paediatr Dent 2017;18(4):279-285. DOI: 10.1007/s40368-017-0297-5.

7. Tamgadge A, Tamgadge $S$, Bhatt $D$, et al. Bilateral dentigerous cyst in a non-syndromic patient: report of an unusual case with review of the literature. J Oral Maxillofac Pathol 2011;15(1):91-95. DOI: 10.4103/0973-029X.80017.

8. Odontogenic and maxilofacial bone tumours. El-Naggar AK, Chan JKC, Grandis JR, et al., ed. WHO classification of Head and Neck Tumours. 4th ed., Lyon: IARC; 2017. pp. 205-260.

9. Jeon JY, Park CJ, Cho SH, et al. Bilateral dentigerous cysts that involve all four dental quadrants: a case report and literature review. J Korean Assoc Oral Maxillofac Surg 2016;42(2):123-126. DOI: 10.5125/ jkaoms.2016.42.2.123.

10. Saluja JS, Ramakrishnan MJ, Vinit GB, et al. Multiple dentigerous cysts in a nonsyndromic minor patient: report of an unusual case. Natl J Maxillofac Surg 2010;1(2):168-172. DOI: 10.4103/0975-5950.79223.

11. Freitas $D Q$, Tempest $L M$, Sicoli $E$, et al. Bilateral dentigerous cysts: review of the literature and report of an unusual case. Dentomaxillofac Radiol 2006;35(6):464-468. DOI: 10.1259/dmfr/26194891.

12. Sandhyarani B, Noorani H, Shivaprakash PK, et al. Fate of pulpectomized deciduous teeth: Bilateral odontogenic cyst? Contemp Clin Dent 2016;7(2):243-245. DOI: 10.4103/0976-237X.183054.

13. da Silva TA, de Sá AC, Zardo M, et al. Inflammatory follicular cyst associated with an endodontically treated primary molar: a case report. ASDC J Dent Child 2002;69(3):271-274. 